\title{
Níveis de nitrogênio associado ao modo de aplicação de regulador de crescimento no
}

\section{algodoeiro}

Nitrogen levels associated with the application of growth regulator in cotton

Niveles de nitrógeno asociados con la aplicación de regulador de crecimiento en algodón

Recebido: 03/01/2021 | Revisado: 04/01/2021 | Aceito: 08/01/2021 | Publicado: 08/01/2021

\author{
Mayara dos Santos Simões \\ ORCID: https://orcid.org/0000-0002-3545-9677 \\ Universidade Estadual de Mato Grosso do Sul, Brasil \\ E-mail:mayarassimoes@hotmail.com \\ Érico Carlos Pedroso \\ ORCID: https://orcid.org/0000-0002-3662-4793 \\ Universidade Estadual de Mato Grosso do Sul, Brasil \\ E-mail: erickarlos2008@gmail.com \\ Matheus Gustavo da Silva \\ ORCID: https://orcid.org/0000-0002-5794-6791 \\ Universidade Estadual de Mato Grosso do Sul, Brasil \\ E-mail: matheus@uems.br
}

\begin{abstract}
Resumo
$\mathrm{O}$ ajuste nas quantidades de nitrogênio, para atender as necessidades nutricionais da cultura, e do regulador de crescimento, para adequar e homogeneizar o porte do algodoeiro é aspecto técnico importante, tendo em vista possibilitar a expressão de todo potencial produtivo das cultivares modernas de algodoeiro. Assim o objetivo desse trabalho foi verificar os efeitos dos modos de aplicação de regulador de crescimento e de doses de nitrogênio em cobertura no desenvolvimento vegetativo e reprodutivo do algodoeiro. O experimento foi desenvolvido na área experimental da Universidade Estadual de Mato Grosso do Sul - Unidade Universitária de Aquidauana (UEMS/UUA), em solo classificado como Argissolo Vermelho distrófico. O delineamento experimental utilizado foi em blocos casualizados, em esquema de parcelas subdivididas $3 \times 4$, com quatro repetições. Os tratamentos foram constituídos pela combinação entre três modos de aplicações de regulador de crescimento (controle sem aplicação, dose única e dose parcelada), utilizando dose recomendada do produto comercial $\left(0,2 \mathrm{~L} \mathrm{ha}^{-1}\right)$, e quatro doses de nitrogênio em cobertura $\left(0,80,160\right.$ e $\left.240 \mathrm{~kg} \mathrm{ha}^{-1}\right)$. Foram avaliadas a altura de planta, altura de inserção do primeiro capulho, diâmetro do caule, massa médio de capulho, rendimento de fibra e a produtividade do algodão em caroço. $\mathrm{O}$ regulador de crescimento reduz a altura das plantas em até $25 \%$ e o diâmetro do caule em aproximadamente 12 \% e aumenta a massa dos capulhos em até 10,2 \%, mas não aumenta o rendimento de fibra e a produtividade de algodão em caroço.
\end{abstract}

Palavras-chave: Adubação nitrogenada; Cloreto de mepiquat; Gossypium spp.; Ácido giberélico; Sulfato de amônio.

\begin{abstract}
The adjustment in the amounts of nitrogen, to meet the nutritional needs of the crop, and the growth regulator, to adapt and homogenize the size of the cotton is an important technical aspect, in order to enable the expression of all the productive potential of modern cotton cultivars. Thus, the objective of this work was to verify the effects of the modes of application of growth regulator and nitrogen doses in coverage on the vegetative and reproductive development of cotton. The experiment was carried out in the experimental area of the State University of Mato Grosso do Sul - University Unit of Aquidauana (UEMS / UUA), in soil classified as dystrophic Red Argisol. The experimental design used was in randomized blocks, in a $3 \times 4$ split plot scheme, with four replications. The treatments consisted of the combination of three modes of growth regulator applications (control without application, single dose and split dose), using the recommended dose of the commercial product $(0.2 \mathrm{~L}$ ha-1), and four doses of nitrogen in coverage $(0,80,160$ and $240 \mathrm{~kg}$ ha-1). Plant height, height of insertion of the first boll, diameter of the stem, average mass of boll, fiber yield and cotton seed yield were evaluated. The growth regulator reduces plant height by up to $25 \%$ and stem diameter by approximately $12 \%$ and increases the mass of bolls by up to $10.2 \%$, but does not increase fiber yield and seed cotton productivity.
\end{abstract}

Keywords: Nitrogen fertilization; Mepiquat chloride; Gossypium spp.; Gibberellic acid; Ammonium sulfate.

\section{Resumen}

El ajuste en las cantidades de nitrógeno, para satisfacer las necesidades nutricionales del cultivo, y el regulador de crecimiento, para adaptar y homogeneizar el calibre del algodón es un aspecto técnico importante, a fin de posibilitar la expresión de todo el potencial productivo de los cultivares de algodón modernos. Así, el objetivo de este trabajo fue verificar los efectos de los modos de aplicación de dosis reguladoras de crecimiento y nitrógeno en cobertura sobre el 
desarrollo vegetativo y reproductivo del algodón. El experimento se realizó en el área experimental de la Universidad Estatal de Mato Grosso do Sul - Unidad Universitaria de Aquidauana (UEMS / UUA), en suelo clasificado como Argisol Rojo distrófico. El diseño experimental utilizado fue en bloques al azar, en un esquema de parcelas divididas $3 \times 4$, con cuatro repeticiones. Los tratamientos consistieron en una combinación de tres modos de aplicación de reguladores de crecimiento (control sin aplicación, dosis única y dosis dividida), utilizando la dosis recomendada del producto comercial $(0.2 \mathrm{~L}$ ha-1), y cuatro dosis de nitrógeno en cobertura. $(0,80,160$ y $240 \mathrm{~kg}$ ha-1). Se evaluó la altura de la planta, altura de inserción de la primera cápsula, diámetro del tallo, masa promedio de cápsula, rendimiento de fibra y rendimiento de semilla de algodón. El regulador de crecimiento reduce la altura de la planta hasta en un $25 \%$ y el diámetro del tallo en aproximadamente un $12 \%$ y aumenta la masa de cápsulas hasta en un $10,2 \%$, pero no aumenta el rendimiento de fibra ni la productividad del algodón en rama.

Palabras clave: Fertilización nitrogenada; Cloruro de mepiquat; Gossypium spp.; Ácido giberélico; Sulfato de amonio.

\section{Introdução}

A cultura do algodão apresenta grande importância na agricultura brasileira, entre os anos-safra de 2006/07 a 2016/17, o Brasil foi responsável, em média, por $6 \%$ da produção mundial de algodão, colocando-o na quinta posição, após China, Índia, Estados Unidos e Paquistão, respectivamente. Nesse mesmo período, o Brasil respondeu por 7,85\% do total de algodão exportado, ocupando também a quinta posição mundial, estando atrás dos Estados Unidos, Índia, Austrália e Uzbequistão (Companhia Nacional de Abastecimento, 2017).

A cultura além de ser destaque na produção vem se destacando também pelo elevado uso de insumos como fertilizantes, inseticidas, herbicidas, fungicidas, corretivos e reguladores de crescimento. Entre os insumos utilizados na cultura do algodão o nitrogênio é considerado essencial para a produtividade do algodoeiro e tornou-se um dos que têm frequentemente causado problemas devido ao mau uso, desencadeando processos de mineralização, lixiviação, desnitrificação e baixa absorção pela cultura, além de seu uso excessivo poder reduzir a produção e a qualidade da fibra (Motomiya et al., 2009).

O nitrogênio é eficaz no desenvolvimento dos órgãos vegetativos, e quando aplicado adequadamente, estimula o crescimento, o florescimento, regula o ciclo da planta, aumenta a produtividade e melhora o comprimento e a resistência da fibra, mas em doses elevadas, ocasiona aumento no desenvolvimento vegetativo da planta, o que prejudica a produção e faz com que ocorra formação tardia dos frutos do algodoeiro (de Nadai Geib et al., 2015).

Para reverter esse efeito de crescimento indesejado na cultura, adota-se o uso de regulador de crescimento, ocasionalmente usado em cultivares de porte alto, e/ou associado à adubação nitrogenada, fazendo com que a distribuição do nutriente seja feita para os drenos produtivos, principalmente quando a cultura está instalada em região de clima e solo favoráveis ao crescimento vegetativo, o que pode resultar em maior produtividade (Ferrari et al., 2008).

Nesse sentido o regulador de crescimento no algodoeiro reduz o tamanho dos internódios, número de nós, altura das plantas, comprimento dos ramos vegetativos e reprodutivos, bem como o número de frutos danificados, folhas na época da colheita, além de aumentar a espessura e dar intensidade na coloração verde das folhas, como também aumentar a retenção de frutos nas primeiras posições dos ramos produtivos, da massa de capulho e do peso de 100 sementes e uniformização da abertura das maçãs (Carvalho et al., 1994).

Nesse contexto formam-se as seguintes hipóteses:

- A aplicação de regulador de crescimento no momento adequado possibilitaria ao algodão a máxima eficiência no uso de nitrogênio mineral?

- O uso de regulador de crescimento e nitrogênio mineral pode contribuir na distribuição de fotoassimilados pelo algodoeiro?

- Até que ponto a relação fonte-dreno é otimizada quando se utiliza nitrogênio mineral associado ao regulador de crescimento? 
Assim, o objetivo do presente trabalho foi verificar efeitos dos modos de aplicação de regulador de crescimento aliados a doses de nitrogênio em cobertura no desenvolvimento vegetativo e reprodutivo da cultura do algodão.

\section{Metodologia}

A pesquisa é experimental realizada a campo, em condições de meio não controláveis, de natureza quali-quanti (Pereira et al., 2018). Foi desenvolvida na área experimental da Universidade Estadual de Mato Grosso do Sul - Unidade Universitária de Aquidauana (UEMS/ UUA), no setor de Fitotecnia, situado no bioma Cerrado, localizado no município de Aquidauana - MS ( $20^{\circ} 27^{\prime} \mathrm{S}$ e $\left.55^{\circ} 40^{\prime} \mathrm{W}\right)$ com altitude média de $170 \mathrm{~m}$.

De acordo com a classificação de Köppen-Geiger, o clima é do tipo Aw (tropical úmido) com verão chuvoso e inverno seco, precipitação média anual de $1200 \mathrm{~mm}$ e com temperaturas medias máxima e mínima de 33 e $19{ }^{\circ} \mathrm{C}$, respectivamente.

Figura 1. Valores médios de temperaturas e precipitações médias pluviométrica no período de janeiro a julho de 2017.

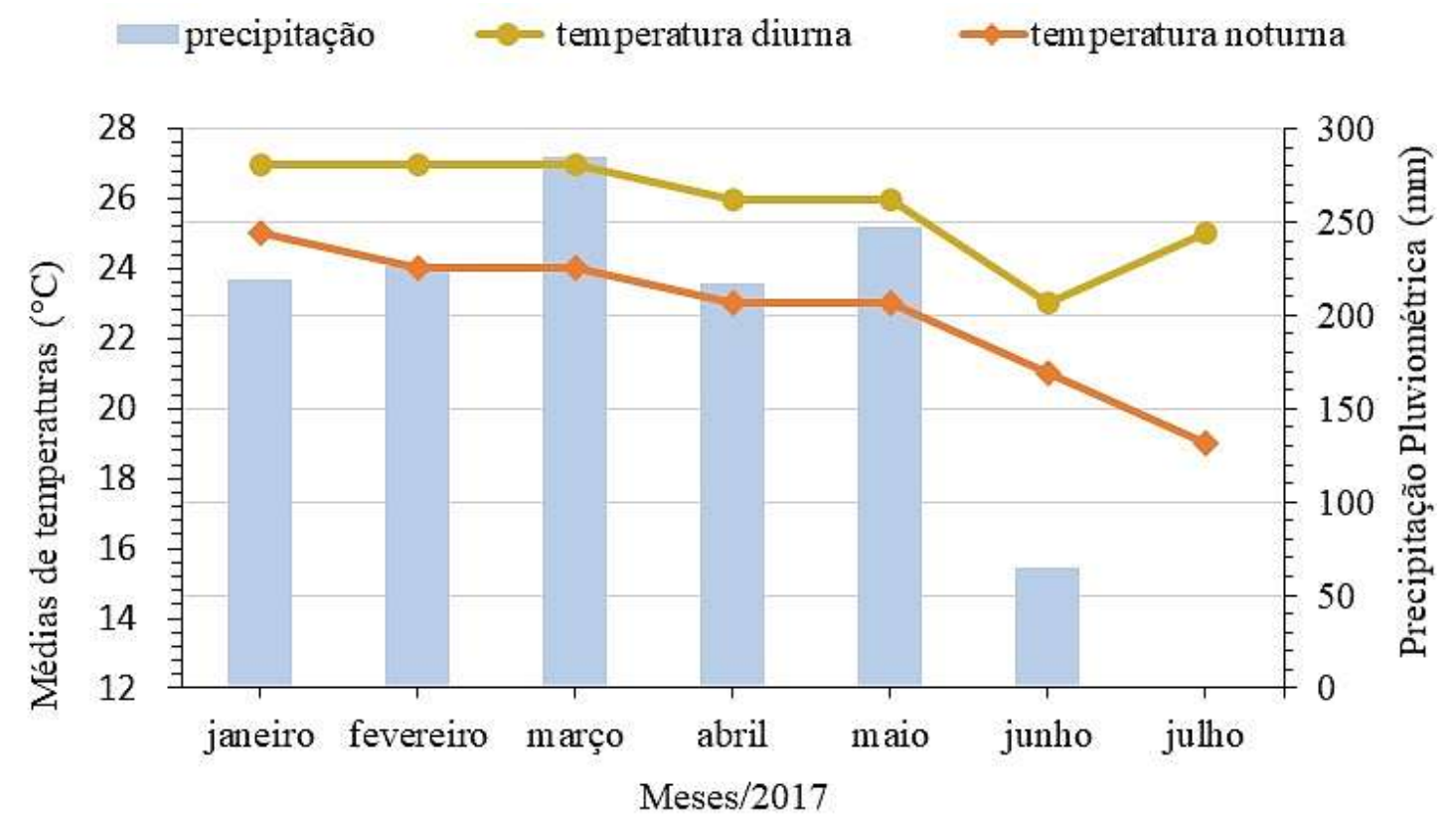

Fonte: Autores.

Na Figura 1, são apresentados os valores médios de temperaturas diurna e noturna e precipitações médias pluviométrica para cada mês de janeiro a julho de 2017 os dados foram obtidos da estação pluviométrica da Universidade Estadual do Mato Grosso do Sul, unidade universitária localizada no município de Aquidauana - MS.

Na Figura 1 pode-se observar que no período do ciclo da cultura, compreendido em sua maior parte no primeiro semestre do ano de 2017, a precipitação ficou concentrada nos meses de janeiro a maio, sendo março e maio os meses com maior volume de precipitação, já as temperaturas diurna e noturna tiveram médias de 26 e $23{ }^{\circ} \mathrm{C}$, respectivamente, sendo janeiro, fevereiro e março os meses com temperaturas mais elevadas, dados obtidos da estação pluviométrica da UEMS Unidade Universitária de Aquidauana.

O solo foi classificado por Schiavo et al. (2010) como Argissolo Vermelho distrófico, de acordo com os critérios de Santos et al. (2018). A análise química do solo na profundidade de $0-20 \mathrm{~cm}$ apresentou os seguintes resultados: pH em água 5,8 , fósforo $20 \mathrm{mg} / \mathrm{dm}^{3}$, MO $11,9 \mathrm{~g} / \mathrm{dm}^{3}$, potássio $0,30 \mathrm{cmol}_{d} / \mathrm{dm}^{3}$, cálcio $2,10 \mathrm{cmol}_{c} / \mathrm{dm}^{3}$, magnésio $0,95 \mathrm{cmol}_{c} / \mathrm{dm}^{3}$, alumínio 0 
$\mathrm{cmol}_{\mathcal{C}} / \mathrm{dm}^{3}, \mathrm{H}+\mathrm{Al} 1,60 \mathrm{cmol}_{\mathcal{C}} / \mathrm{dm}^{3}$, de acordo com essa analise o volume de saturação (v\%) é de $65 \%$, sendo considerado ideal para a cultura do algodão entre 60 e $70 \%$ (Silva, 1999).

O delineamento experimental utilizado foi em blocos casualizados, em esquema de parcelas subdivididas 3x4, com quatro repetições, com os tratamentos constituídos pela combinação entre três modos de aplicações de regulador de crescimento (controle sem aplicação, dose única e dose parcelada), utilizando dose recomendada do produto comercial (0,2 L $\left.\mathrm{ha}^{-1}\right)$, e quatro doses de nitrogênio em cobertura $\left(0,80,160\right.$ e $\left.240 \mathrm{~kg} \mathrm{ha}^{-1}\right)$.

O preparo do solo foi realizado com uma subsolagem, uma gradagem aradora e duas gradagens niveladoras. A semeadura foi realizada manualmente em janeiro de 2017, em densidade de $20 \mathrm{~m}^{2}$ compostas por 4 linhas de 5 metros espaçadas a $0,76 \mathrm{~m}$ com uma população de 10 plantas por metro.

Os tratamentos com regulador de crescimento em dose única foram aplicados no pleno florescimento da cultura, já os tratamentos com dose parcelada foram feitos num primeiro momento quando as plantas atingiram altura média de $0,50 \mathrm{~m}$ de altura e a outra metade em pleno florescimento.

A primeira adubação de cobertura com sulfato de amônio foi realizada aproximadamente 30 dias após emergência (DAE) da cultura, parcelando as maiores doses, $160 \mathrm{~kg} \mathrm{ha}^{-1}$ e $240 \mathrm{~kg} \mathrm{ha}^{-1} \mathrm{em}$ duas e três vezes respectivamente, adotando intervalo de dez dias entre cada aplicação.

Quando as plantas estavam com 50 a $60 \%$ dos capulhos abertos foi realizada a colheita manual e aleatória de 20 plantas de cada parcela. Foram amostradas aleatoriamente 10 plantas, sendo acondicionadas separadamente, para avaliar as variáveis altura de planta, altura de inserção do $1^{\circ}$ capulho, diâmetro do caule, massa média de capulho e rendimento de fibra, seguindo os critérios de avaliação usado por Zanon (2002).

Após a colheita foi determinada a produtividade de algodão em caroço por meio da pesagem da massa de algodão em caroço, extrapolando esses valores para arrobas por hectare (@ ha-1).

Os dados coletados foram submetidos à análise de variância pelo teste F, por meio do software estatístico Sisvar, e as medias foram comparadas pelo teste Tukey a $5 \%$ para o fator qualitativo (épocas de aplicação de regulador de crescimento), enquanto para o fator quantitativo (doses de nitrogênio) utilizou-se análise de regressão.

\section{Resultados e Discussão}

Ocorreu grande volume de precipitação no primeiro semestre no ano de 2017, como citado anteriormente na figura 1, momento em que o algodoeiro estava instalado a campo, causando assim um estresse hídrico na cultura, que é citado por Echer \& Rosolem (2014) como prejudicial ao crescimento do algodão, pois pode ocorrer abortamento facultativo de botões florais e maçãs jovens e a atividade da raiz é prejudicada pelas baixas concentrações de $\mathrm{O} 2$, ocasionando resultados diferentes.

Os valores da análise de variância e os valores médios das variáveis altura de planta, inserção do primeiro capulho, diâmetro do colmo, mediante aplicação de regulador de crescimento e adubação nitrogenada em cobertura, estão apresentados na Tabela 1. 
Tabela 1. Resumo da análise de variância e valores médios para altura de planta, altura de inserção do primeiro capulho, diâmetro do caule, avaliados no momento da colheita, em função do tratamento com regulador de crescimento e doses de nitrogênio em cobertura. Aquidauana, MS (2018).

\begin{tabular}{|c|c|c|c|c|}
\hline \multirow{2}{*}{\multicolumn{2}{|c|}{ Fontes de variação }} & Altura de planta & Altura de inserção do $1^{\circ}$ capulho & Diâmetro do caule \\
\hline & & & $\mathrm{cm}$ & $\mathrm{mm}$ \\
\hline \multirow{3}{*}{ Regulador de crescimento (RC) } & Controle & $1,2 \mathrm{a}$ & $17,3 \mathrm{a}$ & $15,3 \mathrm{a}$ \\
\hline & Dose única & $1,0 \mathrm{~b}$ & 19,3 a & $14,8 \mathrm{ab}$ \\
\hline & Dose parcelada & $0,9 \mathrm{~b}$ & $18,1 \mathrm{a}$ & $13,5 \mathrm{~b}$ \\
\hline \multirow{2}{*}{$\begin{array}{c}\text { D.M.S. } \\
\text { C.V. (RC) }\end{array}$} & & 0,16 & 2,7 & 1,5 \\
\hline & & 14 & 14 & 9 \\
\hline \multirow{4}{*}{ Doses de nitrogênio $(\mathrm{DN}) \mathrm{kg} \mathrm{ha}^{-1}$} & 0 & 1,1 & 18,1 & 14,3 \\
\hline & 80 & 1,0 & 17,4 & 14,6 \\
\hline & 160 & 1,1 & 19,4 & 14,4 \\
\hline & 240 & 1,1 & 18,1 & 15,3 \\
\hline \multirow[t]{2}{*}{ C.V. (DN) } & & 8 & 7 & 10 \\
\hline & $\mathrm{RC}$ & $0,004^{*}$ & $0,149^{\text {ns }}$ & $0,024^{*}$ \\
\hline \multirow[t]{2}{*}{ Valores de F } & $\mathrm{DN}$ & $0,387^{\text {ns }}$ & $0,013^{*}$ & 0,222 ns \\
\hline & $\mathrm{RC} * \mathrm{DN}$ & 0,801 ns & $0,388^{\text {ns }}$ & $0,387^{\text {ns }}$ \\
\hline
\end{tabular}

Médias seguidas de letras iguais na coluna não diferem pelo teste de Tukey a 5\% de significância. * Significativo ao nível de 5\% de significância; ${ }^{\text {ns }}$ Não significativo. D.M.S = Diferença mínima significativa; C.V = Coeficiente de variação.

Fonte: Autores.

Não houve interação entre as doses de nitrogenio e os modos de aplicação do regulador de crescimento $(\mathrm{p}>0,05)$ (Tabela 1), estando de acordo com Furlani Junior et al. (2003) que avaliaram regulador de crescimento em conjunto com doses de nitrogênio não identificando qualquer interação, os autores descrevem que esse resultado se deve à influência de outros fatores do meio, como variação genotípica, condições edafoclimáticas e tratos culturais aplicados à lavoura.

Os dois modos de aplicação do regulador de crescimento, dose única e parcelada, reduziram a altura das plantas em aproximadamente 16 e 25\%, respectivamente (Tabela 1). Resultado semelhante foi obtido por Azevedo et al. (2003) em pesquisa na qual avaliaram o efeito do parcelamento do regulador de crescimento em algodoeiro em condições de irrigação, no Sertão do Estado da Paraíba, observando redução de $25 \%$ em relação à testemunha sem aplicação do regulador de crescimento. A redução na altura com o uso de regulador de crescimento é importante, principalmente quando se refere à necessidade de ajustamento da cultura para colheita mecanizada (Furlani Júnior et al., 2003).

As doses de nitrogênio não interferiram na altura das plantas do algodoeiro (Tabela 1), o que corroborou resultados apresentados por Furlani Junior et al. (2003) estudando densidades (6, 10 e 14 plantas $\mathrm{m}^{-1}$ ), nitrogênio em cobertura (40 e 60 $\mathrm{kg} \mathrm{ha}^{-1}$ ) e modos de aplicação de regulador vegetal (dose única e parcelada), os autores relatam que não houve interferência no crescimento das plantas com uso do nitrogênio. Porém, Lamas \& Staut (2005) ressaltam que genótipos muito produtivos podem ser responsivos às doses superiores a $150 \mathrm{~kg} \mathrm{ha}^{-1} \mathrm{de} \mathrm{N}$, e a cultivar (IAC 22) utilizada por Furlani Junior et al. (2003) se enquadra, por apresentar produtividade superior a $3.600 \mathrm{~kg} \mathrm{ha}^{-1}$ de algodão em caroço (Instituto Agronômico, 1995).

Diferentemente da altura de plantas, a altura de inserção do primeiro capulho não foi alterada com o uso do regulador de crescimento (Tabela 1). Nagashima et al. (2009) ao estudar o desenvolvimento e produção de algodão em condições de campo em espaçamento entre linhas considerado como ultraestreito, submetidos a diferentes doses de regulador de crescimento, observaram redução da altura das plantas, entretanto isso não afetou a altura de inserção do primeiro capulho, proporcionando plantas mais compactas, o que pode melhorar a distribuição de assimilados na planta, manejo, tratos culturais, colheita e a qualidade da fibra por meio da redução de impurezas, como galhos, folhas e cascas dos ramos. 
Os valores de altura de inserção do primeiro capulho de plantas de algodão no momento da colheita em função das doses da adubação nitrogenada estão apresentados na Figura 2.

Figura 2. Inserção do primeiro capulho de plantas de algodão no momento da colheita em função das doses da adubação nitrogenada. Aquidauana, MS (2018).

Fonte: Autores.

A altura de inserção do primeiro capulho foi influenciada positivamente pelas doses de nitrogênio (Tabela 1), assim

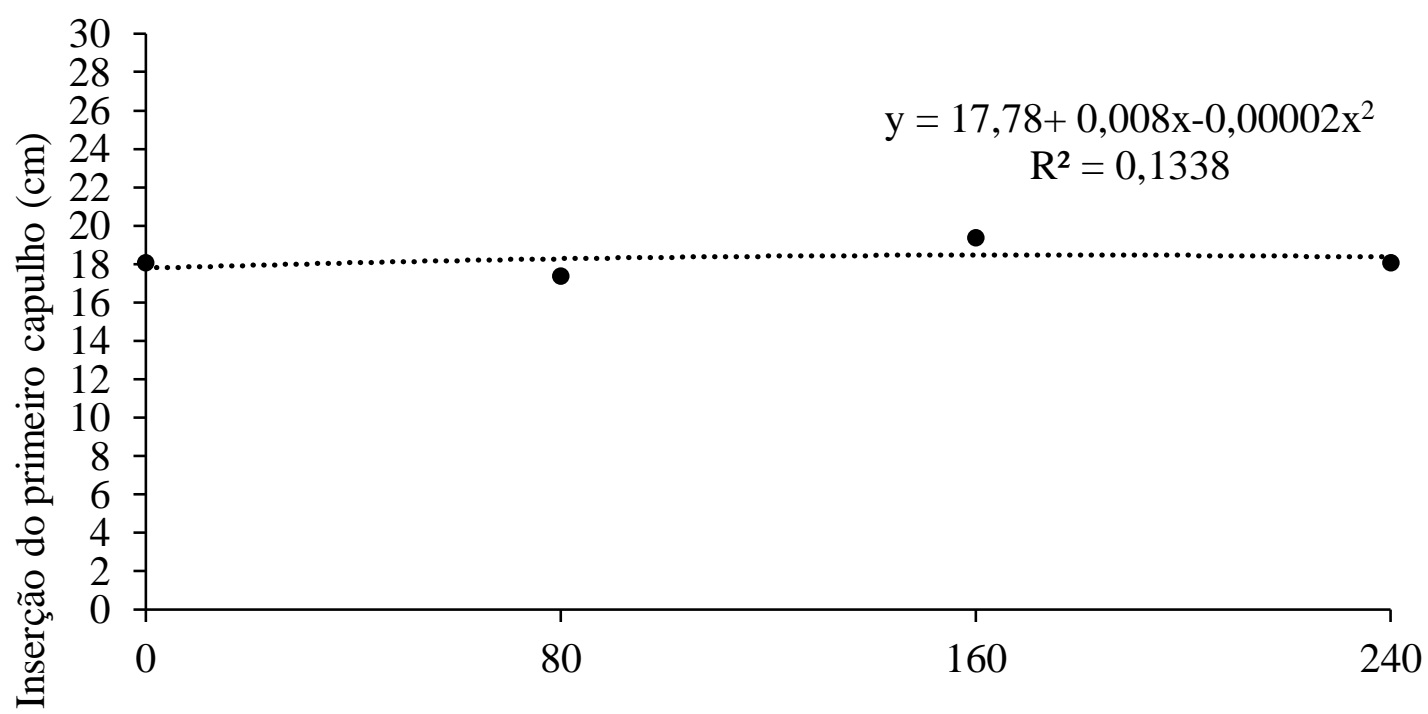

Doses de $\mathrm{N}(\mathrm{kg} / \mathrm{ha})$

pode-se observar na Figura 2 que os dados se ajustaram a equação y = 17,78 + 1,6x - 0,008x², na qual a aplicação de aproximadamente $200 \mathrm{~kg} \mathrm{ha}^{-1}$ de nitrogênio proporcionou uma altura de inserção do primeiro capulho de 19,37 cm. A maior altura de inserção do primeiro capulho é uma característica desejável nos cultivares de algodoeiro para uma melhor eficiência operacional da colheita mecanizada, pois além de evitar o contato dos capulhos com o solo, minimiza as impurezas na fibra (da Silva, 2011).

De forma semelhante à altura de plantas, o diâmetro do caule foi reduzido em aproximadamente $12 \%$ com a aplicação parcelada, do regulador de crescimento (Tabela 1). Utilizando o mesmo regulador aplicado em diferentes épocas, Azevedo et al. (2003) observam resultados semelhantes quando se aplicou o cloreto de mepiquat aos 30 e 60 dias após a emergência (DAE), alcançando redução de até $20 \%$ no diâmetro do caule. Isso ocorreu porque o cloreto de mepiquat inibe a síntese do ácido giberélico, que por sua vez regula a atividade do cambio vascular e a diferenciação dos tecidos do sistema vascular secundário, influenciando no crescimento em largura do caule (Taiz et al., 2017).

As doses de nitrogênio não alteraram o diâmetro do caule, com os valores variando aproximadamente $7 \%(\bar{x}=$ 14,5 mm) (Tabela 1), diferentemente de Lima et. al (2006) que observaram acréscimos do diâmetro com a aplicação de nitrogênio, obtendo médias em torno de $9,7 \mathrm{~mm}$, com uma variação de $10 \%$ entre a testemunha e a aplicação de $160 \mathrm{~kg}$ ha-1 de nitrogênio. A explicação pelo resultado distinto se da pelo fato de que os autores conduziram o experimento em casa de vegetação, podendo assim ter o ambiente controlado protegendo as plantas de quaisquer parâmetros meteorológicos adversos. Nesse sentido, pode ser que a ausência de efeitos do nitrogênio sobre o diâmetro do caule, como para a altura de plantas, é influenciada principalmente por fatores ambientais (Taiz et al., 2017).

Os valores da análise de variância e valores médios para massa de 10 capulhos, rendimento de fibra e produtividade em função do tratamento com regulador de crescimento e doses de nitrogênio em cobertura estão dispostos na Tabela 2. 
Tabela 2. Análise de variância e valores médios para massa de 10 capulhos, rendimento de fibra e Produtividade em função do tratamento com regulador de crescimento e doses de nitrogênio em cobertura. Aquidauna (2018).

\begin{tabular}{|c|c|c|c|c|}
\hline \multirow{2}{*}{\multicolumn{2}{|c|}{ Fontes de variação }} & \multirow{2}{*}{$\begin{array}{c}\text { Massa de capulho } \\
\mathrm{g}\end{array}$} & \multirow{2}{*}{$\begin{array}{c}\text { Rendimento de fibra } \\
\%\end{array}$} & \multirow{2}{*}{$\begin{array}{c}\text { Produtividade em caroço } \\
\mathrm{kg} \mathrm{ha}^{-1}\end{array}$} \\
\hline & & & & \\
\hline & Controle & $4,6 \mathrm{ab}$ & $42,1 \mathrm{a}$ & $718,0 \mathrm{a}$ \\
\hline \multirow[t]{2}{*}{ Regulador de crescimento (RC) } & Dose única & $4,4 \mathrm{~b}$ & $42,0 \mathrm{a}$ & $512,5 \mathrm{a}$ \\
\hline & Dose parcelada & $4,9 \mathrm{a}$ & $41,5 \mathrm{a}$ & $483,6 \mathrm{a}$ \\
\hline \multicolumn{2}{|l|}{ D.M.S. } & 0,4 & 1,3 & 299,7 \\
\hline \multicolumn{2}{|l|}{ C.V. (RC) } & 8 & 3 & 48 \\
\hline & 0 & 4,8 & 42,3 & 583,1 \\
\hline Doses de nitrogênio (DN) & 80 & 4,8 & 42,0 & 571,7 \\
\hline \multirow[t]{2}{*}{$\mathrm{kg} \mathrm{ha}^{-1}$} & 160 & 4,5 & 41,5 & 499,5 \\
\hline & 240 & 4,5 & 41,8 & 631,2 \\
\hline \multicolumn{2}{|l|}{ C.V. (DN) } & 7 & 3 & 31 \\
\hline \multirow{3}{*}{ Valores de F } & $\mathrm{RC}$ & $0,028^{*}$ & $0,376^{\mathrm{ns}}$ & $0,102^{\mathrm{ns}}$ \\
\hline & $\mathrm{DN}$ & $0,128^{\mathrm{ns}}$ & $0,378^{\mathrm{ns}}$ & $0,360^{\mathrm{ns}}$ \\
\hline & $\mathrm{RC} * \mathrm{DN}$ & $0,753^{\mathrm{ns}}$ & $0,927^{\mathrm{ns}}$ & $0,395^{\mathrm{ns}}$ \\
\hline
\end{tabular}

Médias seguidas de letras iguais na coluna não diferem pelo teste de Tukey a 5\% de significância; *Significativo ao nível de $5 \%$ de

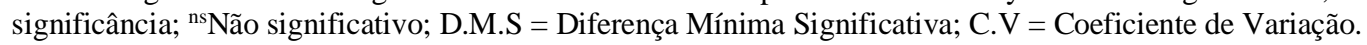

Fonte: Autores.

O regulador de crescimento quando aplicado parceladamente aumentou 10,2\% e 6,1\% a massa de capulhos comparativamente a sua aplicação em dose única e controle (Tabela 2), respectivamente. Furlani Júnior et al. (2003) estudando modos de aplicação de regulador vegetal no algodoeiro, em diferentes densidades populacionais e doses de nitrogênio em cobertura, também constataram que essa variável teve maior crescimento com o parcelamento da aplicação de regulador de crescimento em quatro vezes desde o desbaste. Segundo os autores, isso está relacionado ao fato do regulador de crescimento, reduzir o desenvolvimento vegetativo e assim promover melhor formação de maçãs devido aos desvios metabólicos dos fotoassimilados.

As doses de nitrogênio não influenciaram a massa de capulhos (Tabela 2), corroborando com Kaneko (2013) e Furlani Júnior et al. (2003) que ao avaliarem a resposta do algodoeiro a aplicação de nitrogênio, também concluíram que a variável não foi influenciada pelo tratamento. Segundo Lamas (2001) a massa dos capulhos é influenciada diretamente pelo equilíbrio entre as partes vegetativas e reprodutivas da planta, indicando assim que a adubação nitrogenada não alterou este equilíbrio, para as condições em que foi realizado o experimento.

Para o rendimento de fibra o regulador de crescimento não houve efeito significativo (Tabela 2). Nagashima et al. (2009) usando regulador de crescimento via embebição de sementes e aplicação foliar em algodoeiro em espaçamento ultraestreito $(0,30 \mathrm{~m})$ afirmaram que os modos de aplicação de regulador de crescimento não interferiram no rendimento de fibra. Resultados semelhantes foram encontrados na literatura por Furlani Junior et al. (2003) e Zanqueta et al. (2004). Os efeitos do regulador de crescimento na cultura do algodoeiro são dependentes de vários fatores, podendo ser destacados: a cultivar, época de semeadura, população de plantas, dose e época de aplicação, temperatura, fertilidade do solo e disponibilidade de água para as plantas (Athayde \& Lamas, 1999).

As doses de nitrogênio também não alteraram o rendimento de fibra (Tabela 2). Vieira et al. (2003), ao estudar doses de nitrogênio sobre as características da fibra, retenção frutífera e componentes da produção do algodoeiro, não verificaram 
influência do nutriente em tal variável utilizando até $150 \mathrm{~kg} \mathrm{ha}^{-1}$ de N. Uma das características desejáveis para os genótipos é que o rendimento de fibra seja igual ou superior a 40\% (Farias et al., 1999). Verificou-se nas condições estudadas, rendimento de fibra em torno de $42 \%$, sendo, portanto, considerada dentro das características desejáveis para esta variável.

A produtividade de algodão em caroço não foi influenciada pelo regulador de crescimento (Tabela 2), corroborando dados apresentados por Kerby et al. (1985), Hodges et al. (1991) e Nagashima et al. (2007) que também não tiveram a produtividade de algodão em caroço influenciada pelo regulador de crescimento. Acréscimos de produtividade de algodão em caroço podem ocorrer por meio do equilíbrio entre o desenvolvimento de partes vegetativas e reprodutivas, pois o uso de regulador tem a função de melhorar a distribuição de fotoassimilados nas plantas (Kerby et al., 1986).

Resultados diferentes de produtividade com o uso de regulador de crescimento são devido a distintos tipos de solo e clima encontrados nas diferentes regiões do país, como também a época de semeadura, uma vez que o algodoeiro se mostra bastante sensível as condições de luminosidade, temperatura e déficit ou excesso de água (Lamas \& Ferreira, 2015).

As doses de nitrogênio não influenciaram a produtividade de algodão em caroço (Tabela 2). Em trabalho envolvendo épocas de aplicação de dose de N, Carvalho et al. (2005) também não observaram efeito do N sobre a produtividade de algodão em caroço, o que segundos os autores podem ser explicado pela elevada precipitação pluviométrica durante todo o ciclo da cultura, o que também ocorreu neste trabalho.

A produtividade do algodoeiro é mais sensível ao encharcamento que ocorre até a metade do período de florescimento (Bange et al., 2004). Dependendo da duração do estresse, pode promover aumento na percentagem da queda dos botões florais e o "shedding" dos frutos jovens (Beltrão, 2002). Há relatos em que as reduções de produtividade podem ser de até 2,4\% por dia de encharcamento ou $40 \%$ no fim da safra (Echer \& Rosolem, 2014).

Em razão do excesso de água no solo ser um dos prováveis motivos de perda e redução da produtividade da cultura do algodão, pode-se explicar a baixa produtividade da cultura no presente trabalho em que o solo da área experimental ficou em estado de encharcamento por vários períodos, devido à concentração de precipitação pluviométrica em alguns meses do ano de 2017, como apresentado anteriormente na Figura 1.

\section{Conclusões}

Para as condições experimentais em que este experimento foi conduzido conclui-se que:

1. Não houve efeito interativo do nitrogênio e do regulador de crescimento no desenvolvimento vegetativo e reprodutivo da cultura do algodão.

2. O regulador de crescimento reduz a altura das plantas e o diâmetro do caule, aumenta a massa dos capulhos, mas não aumentou o rendimento de fibra e a produtividade de algodão em caroço.

Sabendo da importância de trabalhos que estudam o nitrogênio como principal nutriente para a produção do algodão como também estudos com o uso de regulador de crescimento para evitar uma serie de inconvenientes para a cotonicultura, como excesso no crescimento vegetativo favorecendo o apodrecimento das maças (frutos) resultando em perda de produtividade, sugere-se mais pesquisas que abranjam em conjunto o nitrogênio e o regulador de crescimento e em experimentos a campo com influencias do meio e edafoclimáticas, e não em ambiente controlado, pois assim os resultados serão mais próximos da realidade da cotonicultura.

\section{Referências}

Athayde, M. L. F., \& Lamas, F. M. (1999). Aplicação seqüencial de cloreto de mepiquat em algodoeiro. Pesquisa Agropecuária Brasileira, 34(3), 369-375. https://doi.org/10.1590/S0100-204X1999000300007

Bange, M. P., Milroy, S. P., \& Thongbai, P. (2004). Growth and yield of cotton in response to waterlogging. Field Crops Research, 88(2-3), 129-142. https://doi.org/10.1016/j.fcr.2003.12.002 
Beltrão, N. E. de M. (2002). Anoxia - Algodão sem ar. Revista grandes culturas. (37), 10-11. https://www.grupocultivar.com.br/artigos/anoxia-algodao-semar.

Carvalho, L. H., Chiavegato, E. J., Cia, E., Kondo, J. I., Sabino, J. C., Pettinelli Júnior, A., \& Gallo, P. B. (1994). Fitorreguladores de crescimento e capação na cultura algodoeira. Bragantia, 53(2), 247-254. https://www.researchgate.net/profile/Edivaldo_Cia/publication/262497730_Effects_of_growth _phytoregulators_and_pruning_on_the_cotton_crop/links/5560c74308ae8c0cab31ebcd/Effects-of-growth-phytoregulators-and-pruning-on-the-cottoncrop.pdf.

Carvalho, M. C. S., Barbosa, K. A., Piccolo, M. C., Leandro, W. M., \& Oliveira Júnior, J. P. (2005). Doses e épocas de aplicação de nitrogênio na cultura do algodoeiro cultivado em sistema plantio direto. In: Congresso Brasileiro De Algodão (Vol. 5).

Companhia Nacional de Abastecimento (CONAB). (2017). Compêndio de Estudos da CONAB, 2017. https://www.conab.gov.br.

da Silva, R. P., Ferreira, I. C., \& Cassia, M. T. (2011). Perdas na colheita mecanizada de algodão. Scientia Agropecuaria,2(1), 7-12. https://dialnet.unirioja.es/servlet/articulo? codigo=3709083.

de Azevedo, D. M. P., Bezerra, J. R. C., Alves, I., Pereira, J. R., Brandão, Z. N., \& Jerônimo, J. F. (2003). Parcelamento do cloreto de Mepiquat no crescimento e na produção do algodoeiro irrigado. Embrapa Algodão. https://ainfo.cnptia.embrapa.br/digital/bitstream/CNPA/16665/1/COMTEC189.PDF.

de Nadai Geib, L. R., Amado, T. J. C., Bragagnolo, J., Bortolotto, R. P., \& Dalla Nora, D. (2015). Resposta da produtividade do algodoeiro em diferentes doses de nitrogênio e eficiência do sensor óptico em estimar o potencial produtivo. Revista engenharia na agricultura-reveng, 23(1), 57-64. https://doi.org/10.13083/reveng.v23i1.522

dos Santos, H. G., Jacomine, P. K. T., Dos Anjos, L. H. C., De Oliveira, V. A., Lumbreras, J. F., Coelho, M. R., \& Cunha, T. J. F. (2018). Sistema Brasileiro De Classificação De Solos.: Embrapa, 2018.

Echer, F. R. (2014). O algodoeiro e os estresses abioticos: temperatura, luz, água e nutrientes. Embrapa Agropecuária Oeste-Outras publicações científicas (ALICE).

Farias, J. C. F., Beltrão, N. D. M., \& Freire, E. C. (1999). Caracteres de importância econômica no melhoramento do algodoeiro. O agronegócio do algodão no Brasil (Beltrão NE de M., ed). EMBRAPA-Comunicação para transferência de tecnologia, 361-370.

Ferrari, S., Furlani Júnior, E., Ferrari, J. V., Santos, M. L., \& Santos, D. M. A. D. (2008). Desenvolvimento e produtividade do algodoeiro em função de espaçamentos e aplicação de regulador de crescimento. Acta Scientiarum. Agronomy, 30(3), 365-371. https://doi.org/10.4025/actasciagron.v30i3.3546

Furlani Junior, E., Silva, N. M. D., Carvalho, L. H., Bortoletto, N., Sabino, J. C., \& Bolonhezi, D. (2003). Modos de aplicação de regulador vegetal no algodoeiro, cultivar IAC-22, em diferentes densidades populacionais e níveis de nitrogênio em cobertura. Bragantia, 227-233. https://www.scielo.br/pdf/brag/v62n2/v62n2a07.

Hodges, H. F., Reddy, V. R., \& Reddy, K. R. (1991). Mepiquat chloride and temperature effects on photosynthesis and respiration of fruiting cotton. Crop Science, 31(5), 1302-1308. https://dx.doi.org/10.2135/cropsci1991.0011183X003100050044x.

Instituto Agronômico (IAC). (1995). Cultivar De Algodoeiro Iac 22. Boletim técnico-Informativo do instituto agronômico: o agronômico. (47-50). http://www.iac.sp.gov.br/cultivares/inicio/Folders/Algod\%C3\%A3o/IAC-22.htm.

Kaneko, F. H., Leal, A. J. F., Anselmo, J. L., Buzetti, S., \& Tosta, F. D. S. (2013). Fontes e manejos da adubação nitrogenada em algodoeiro. Pesquisa agropecuária tropical, 43(1), 57-63. https://doi.org/10.1590/S1983-40632013000100002.

Kerby, T. A. (1985). Cotton Response to Mepiquat Chloride 1. Agronomy Journal,77(4), 515-518. https://dx.doi.org/10.2134/agronj1985.00021962007700040003x.

Kerby, T. A., Hake, K., \& Keeley, M. (1986). Cotton Fruiting Modification with Mepiquat Chloride 1. Agronomy Journal,78(5), 907-913. https://dx.doi.org/10.2134/agronj1986.00021962007800050032x.

Lamas, F. M., \& Ferreira, A. C. de B. (2015). Reguladores de crescimento, desfolhantes e maturadores. In: Freire, E. C. (Ed.). Algodão no Cerrado do Brasil. ( p. 778-786). (3a. ed.): Abrapa.

Lamas, F. M., \& Ferreira, A. D. B. (2011). Reguladores de crescimento, desfolhantes e maturadores. Embrapa Agropecuária Oeste- Capítulo em livro cientifico (ALICE). http://dx.doi.org/10.1590/S0100-204X2001000200008.

Lamas, F. M., \& Staut, L. A. (2005). Nitrogênio e cloreto de mepiquat na cultura do algodoeiro. Revista Ceres, 51(298), 755-764. http://www.ceres.ufv.br/ojs/index.php/ceres/article/view/3016/902.

Lima, M. M. D., de Azevedo, C. A., Beltrão, N. E. D. M., Dantas Neto, J., Gonçalves, C. B., \& Santos, C. G. D. F. (2006). Nitrogênio e promotor de crescimento: efeitos no crescimento e desenvolvimento do algodão colorido verde. Revista Brasileira de Engenharia Agrícola e Ambiental, 10(3), 624-628. http://dx.doi.org/10.1590/S1415-43662006000300013

Motomiya, A. V. D. A., Molin, J. P., \& Chiavegato, E. J. (2009). Utilização de sensor óptico ativo para detectar deficiência foliar de nitrogênio em algodoeiro. Revista Brasileira de Engenharia Agrícola e Ambiental, 13(2), 137-145. https://doi.org/10.1590/S1415-43662009000200005

Nagashima, G. T., Miglioranza, É., Marur, C. J., \& Yamaoka, R. S. (2009). Cloreto de mepiquat via embebição de sementes e aplicação foliar em algodoeiro em espaçamento ultraestreito. Revista Ciência Agronômica, 40(4), 602-609. http://ccarevista.ufc.br/seer/index.php/ccarevista/article/view/462/388.

Nagashima, G. T., Miglioranza, É., Yamaoka, R. S., \& Gomes, J. C. (2007). Soaking seeds and foliar application with mepiquat chloride on growth and yield of cotton plant. Ciência e Agrotecnologia, 31(4), 1027-1034. https://doi.org/10.1590/S1413-70542007000400013 
Research, Society and Development, v. 10, n. 1, e21810111647, 2021

(CC BY 4.0) | ISSN 2525-3409 | DOI: http://dx.doi.org/10.33448/rsd-v10i1.11647

Pereira, A. S., Shitsuka, D. M., Parreira, F. J., \& Shitsuka, R. (2018). Metodologia da pesquisa científica. Ed. UAB/NTE/UFSM. https://repositorio.ufsm.br/bitstream/handle/1/15824/Lic_Computacao_Metodologia-Pesquisa-Cientifica.pdf?sequence=1.

Schiavo, J. A., Pereira, M. G., Miranda, L. P. M. D., Dias Neto, A. H., \& Fontana, A. (2010). Caracterização e classificação de solos desenvolvidos de arenitos da formação Aquidauana-MS. Revista Brasileira de Ciência do Solo, 34(3), 881-889. https://doi.org/10.1590/S0100-06832010000300029

Silva, N. D. (1999). Nutrição mineral e adubação do algodoeiro no Brasil. Cultura do algodoeiro. Piracicaba, Potafos, 57-92. https://www.scielo.br/scielo.php?script=sci_nlinks\&ref=000169\&pid=S1415-4366200900020000500027\&lng=en.

Taiz, L., Zeiger, E., Møller, I. M., \& Murphy, A. (2017). Fisiologia e desenvolvimento vegetal. Artmed Editora.

Vieira, R. D. M., de Medeiros, A. A., Amorim, J. A., \& da Fonseca, F. D. C. E. (2003). Influência do nitrogênio sobre as características da fibra, retenção frutífera e componentes da produção do algodoeiro. Revista Brasileira de Oleaginosas $e$ Fibrosas, 7(1). https://www.scielo.br/scielo.php?script=sci_nlinks\&ref=000120\&pid=S0006-8705200800040001 100017\&lng=en.

Zanon, G. D. (2002). Manejo de cultivares de algodoeiro em densidade populacional variável com o uso de regulador de crescimento (Doctoral dissertation, Universidade de São Paulo). https://www.teses.usp.br/teses/disponiveis/11/11136/tde-08012003-091325/en.php.

Zanqueta, R., Junior, E. F., Pantano, A. C., \& de Souza, R. A. R. (2004). Modos de aplicação de regulador de crescimento com diferentes densidades de plantas em cultivares de algodão herbáceo (Gossypium hirsutum L. var. latifolium Hutch. Acta Scientiarum. Agronomy, 26(1), 97-105. https://doi.org/10.4025/actasciagron.v26i1.1966. 